\title{
The Inclusion Assistant: Who Is She Supposed to Be? An Exploratory Study
}

\author{
Anat Moshe, Perach Licht" \\ Department of Special Education, Beit Berl Academic College, Israel
}

Copyright $\bigcirc 2016$ by authors, all rights reserved. Authors agree that this article remains permanently open access under the terms of the Creative Commons Attribution License 4.0 International License

\begin{abstract}
Following the almost worldwide implementation of policies giving all students - including those with special education needs - the right to learn within the general education system, there has been a sharp increase in the number of inclusion assistants (IA). IAs provide special-needs students one-to-one accompaniment, allowing them to function in the general education classroom and reducing the onus on the classroom teacher in such cases. Unfortunately, many, if not most, of IAs enter the system without suitable training or special qualifications and often neither they nor the teachers have a clear idea of how they should fulfill their role. This exploratory study used a questionnaire and semi-structured interviews to identify and compare how 30 classroom teachers and IAs define the IA's role. It also studied how eight IAs changed their perception of their roles after attending an IA training course and what the implications of such courses may be. The findings indicated that there is a discrepancy in how teachers and IAs define the IA's role, indicating a need for clearer delineations. The results also indicated the necessity for creating a suitable framework for teaching IAs the theoretical and practical aspects of the job.
\end{abstract}

Keywords Inclusion Assistant, Students with Special Educational Needs, Professional Training

\section{Introduction}

\subsection{Teaching Assistants Worldwide}

In the past two decades, educational systems in the Western world have been undergoing widespread changes regarding the perceptions, attitudes, and nature of the services given to students with special educational needs (SEN). Most notable of these changes is the demand formulated as part of an international agreement and that has been secured through the passage of laws that demand the inclusion of SEN students into the general education setting
$[1,2]$.

In Israel, as in most of the world, special education laws have been enacted. These laws require the inclusion of students with special educational needs into the general education setting, not only from the physical aspect, but also to meet there academic, emotional and social needs on a level that is adapted to each student personally [3-5]. Thus, there is growing attention focused on a new type of TA referred to as an "inclusion assistant" (IA), who serves as a personal assistant to help an individual SEN student in the general setting. Because this historic change in policy has brought about a dramatic rise in the number of students with severe disabilities that are eligible for an IA, there has been an increase of teaching assistants who are employed as IAs in the general education setting.

The result is a sharp rise in the number of students with severe disabilities who are included in the in the general education setting has brought about a change in the essence of the IA's role who is now responsible for integrating SEN students in general and students with more severe disabilities in particular. In contrast to the past, where the TA was employed in special classrooms and worked in tandem with a special education teacher, today, an IA works in the general education setting.

As part of the studies evaluating the success of these students' inclusion and their level of functioning, the role of the IA and their contribution to the process were examined. It was found that the two most significant influences on the success of SEN students were the IA's training and the relationship between the teacher and the IA [5-9].

The UK has reported a dramatic rise in the number of assistants. In 1997, there were 70,300 assistants employed in both the general and special-education settings. This jumped to 178,900 in 2009 . Studies that examined teacher-assistant cooperation and support showed that a clear definition of the roles, precise division of responsibilities, and mutual appreciation of the other's contribution to the team effort were the prime factors in the feelings of satisfaction that each had from their roles and, most importantly, the student's successful inclusion [7-9].

The United States placed much emphasis on the training 
of the IA as a condition of successful inclusion, yet in practice, the training and support of the IA falls on the classroom teacher. Studies such as those by Appl [10] have shown that novice teachers do not have the proper knowledge to monitor and support an IA since they never received appropriate training as part of their education prior to taking up their teaching role.

In Finland, the number of assistants in schools has risen $48 \%$ since the 1990 s, whereas the number of teachers has risen only $18 \%$. This reflects the increase in the number of SEN students in the general education setting. A study by Takala [11] that examined the teachers' perception of the role of assistant illuminated many complex issues that an IA is expected to address both regarding education and learning, and being involved in activities inside and outside the class (transportation, recess, etc.). The study emphasized that this most complex of jobs is carried out by personnel that have the least professional training in the system, since IAs do not undergo any kind of comprehensive training and receive a low salary.

\subsection{Teaching Assistants in Israel}

The Law of Special Education that was enacted in 1988 regulated the rights of SEN students to receive education and care according to their needs. The law grants special-education services to "every person from the age of three to twenty-one years who, as a result of a developmental deficiency, whether physical, intellectual, emotional, or behavioral, is limited in his or her adaptive behavior, and requires special education" [12-14].

According to section 2 of the law, "the goal of special education is to promote the skills and ability of the exceptional child, to correct and improve his physical, intellectual, emotional or behavioral functions; and to provide knowledge, skills, and routines that will allow the child to attain societally-accepted behavioral patterns, with a goal to facilitating the individual's inclusion into society and the workforce" [14].

In 2002, Amendment no. 7 - the "Inclusion Law" - was approved and section D-1 that was added endorsed integrating SEN students into the general educational system. This amendment allows students with special needs, and especially those with severe disabilities and functionality problems to be included into the general education setting, through the addition of teaching hours and the amount of special services provided.

This section details the special services provided in the inclusion framework for the SEN student: support in learning, support in compatibility, and one-to-one assistance. A student's eligibility to receive this type of assistance is determined by the type of disability and functional level as defined by the Director General Circular (DGC). The disabilities for which IA support can be approved include cerebral palsy, severe physical disabilities, blindness, autism, moderate-level intellectual development disabilities, emotional disorders, and rare conditions and syndromes that require constant supervision. The amendment specifies that the government is responsible for financing the required support services (that is to say, the para-medical and pedagogic staff, and the assistants), required by the SEN students included in the general education setting. The decision regarding allocating an IA and the number of hours budgeted depends on the functional level of the student as based on detailed criteria defined by the Ministry of Education.

Final approval is given only at the beginning of the academic year, as it is carried out by the Ministry of Education and not by the institution (school) itself.

According to the report issued by the Dorner Committee (a public committee headed by Judge Dalia Dorner to study the special education system in Israel) [15], as a result of the application of the inclusion law, the number of inclusion students, particularly those with severe disabilities has risen sharply. In 2007, 128,000 children with special needs studied in the education system: $42 \%(53,760)$ in special-education frameworks and $58 \%(74,240)$ in the general educational system. By the 2011-2012 academic year, there were 203,000 SEN students in the Israeli school system: $64.5 \%$ studied in the general education system and only $35.5 \%$ in special-education frameworks (and these mostly small classes situated within the general schools) [16]. Simultaneously, there has been a rise in the number of IAs assigned to SEN students with a parallel rise in the importance of their position and functions.

A number of DGCs issued between 1998 and 2011 describe three types of teaching assistants [12, 17-19]. This study focuses on the third type.

a Class assistants: These assistants work within the special education framework. The directors of the educational institutions are responsible for hiring them.

b Institutional reinforcement assistants: These work in special education classrooms that are not eligible for a class assistant.

c Inclusion assistants (IA): IAs serve as part of the inclusion services offered to individual SEN students.

DGC 4371/10(a) [19] also deals with policies for employing assistants to support SEN students in both institutions of special education and in the general education setting. It addresses the IA' role, when she is expected to work throughout the year and during vacation times, reporting procedures with respect to the contribution of the office that hired the IA, and allocating funds for the IA in accordance with the type of educational institution and the range of disabilities. As the DGC suggests, the IA has many and varied roles that can be divided into two separate functional areas: functional and educational. The functional area includes meeting the student as he or she arrives in the morning and accompanying him to meet his ride at the end of the day, assisting with hygiene, helping to navigate from 
place to place, and so on. The educational aspect covers helping the student do the assignments during class and participating in staff meetings in accordance to the directives of the professional staff in the school.

Comparing this more recent DGC to previous ones reveals that the definitions of the types of assistants and their role have not changed over the years, despite the fact that the change in policy regarding the inclusion of SEN students should have demanded a revision of the role of the IA to apply to students with different and more severe disabilities than in the past.

\subsection{Requirements for the IA - Education and Training}

DGC 4371/10(a) [19] states than the only qualification required for the role of IA is the completion of at least twelve years of learning.

Nevertheless, it mentions the issue of training for an IA: "The Ministry of Education, in collaboration with the Ministry of the Interior and local authorities will prepare a professional development program for IAS covering topics relevant to their work. Such programs will grant the teaching assistant a diploma confirming completion of the relevant courses, and which will allow them to receive appropriate remuneration as a result of their participation in the course, in accordance with the criteria and policies of the local administration."

The emphasis, though, is on in-service professional development that occurs after the individual has begun working as an IA, and that is dependent on the policies of the local authorities. It does not require the IA to obtain a certificate prior to her employment.

As part of the deliberations concerning the various issues for SEN students, Minister of Education (at the time) Prof. Yuli Tamir decided to convene a public committee to examine the special-education situation in Israel. In 2009, the committee, headed by former Supreme Court judge Dalia Dorner, presented a report to the Knesset (Israeli house of representative), that included references to the role and training of the IA:

a) Inclusion assistants-The committee decided not to interfere with the Ministry of Education's policy, which recommended reducing support for IAs. However, they recommended that this policy be revised periodically based on new studies and field experience.

b) State supervision-The Ministry of Education should oversee the budget allocated to the local authorities to ascertain that it is indeed being utilized only for the funding of IAs.

c) Training-The Ministry of Education should ensure that IAs undergo a 400-hour certification program.

Although training programs for teaching assistants are offered in a number of higher-education institutions in Israel, none of the programs are more than even 200 hours in length. These are Shalom College in Beer Sheva (180 academic hours in 36 session over 5 months); Beit Izzy Shapira, Raanana (120 hours in 30 weekly sessions); College of Management Academic Studies (200 hours over nine months, meetings twice a week); ORT Israel (200 hours over eight months). These courses are intended for those who are already working as a TA or IA in the field of special education but who have not yet undergone any formal training in the field. They are also suitable for anyone wishing to prepare themselves for future employment in this challenging and interesting field.

Despite the existence of such programs, it is important to recognize that completing such a program is not a condition of acceptance to the positions in question. In fact, it has been demonstrated that there is no widespread training of this kind. Thus, a situation has been created in the past years in which, despite a significant rise in the number of inclusion students with a wide range of severe disabilities, the IAs, who play such a significant role in the integration of such students, lack any appropriate training. Furthermore, the teachers in the integrated classes, who should ostensibly be guiding the IA, also have not received training regarding dealing with children of this nature.

The reality, therefore, is that the very personnel who are directly working with these challenging students lack any appropriate professional training. In fact, the many, varied demands of this position are incompatible with the professional abilities (or lack thereof) of those who fill it.

\subsection{Research Goals}

This exploratory two-stage study was designed to lay the foundation for a future, wide-spectrum study that would investigate the roles of the IA, and define the features and structure required for training for this role.

The first stage of the study focused on the following goals:

- Identifying and mapping the role of the IA as perceived by teachers and IAs

- Comparing the IAs' and teachers' perceptions of the role of the IA regarding the various aspects of the IA's role

- Assessing the consequences of these aspects on the training of the IA for SEN students in the general education setting.

The second stage took place after a number of IAs participated in a brief training course and focused on the impact of a brief IA's training on the perception of the IA's role.

\section{Method}

This study attempts to assess how the IAs perceive their role with SEN students in the general classroom and compare it to how the classroom teachers perceives their role. It also investigates the effect that a professional development course had on the IAs' perception of their roles. 


\subsection{Participants}

The study was divided into two stages. In the first stage of the study, 30 participants (18 teachers with SEN students in their classes, some of whom were accompanied by IAs, and 12 IAs who work with students with severe disabilities) took part. All worked in general classes in public schools in the center of the country.

The second stage assessed the perceptions of eight IAs who participated in a 20-hour course (one segment of a year-long program) on the subject of children with special needs and the role of the IA in the education system.

Tables 1 and 2 present background information (position, experience, education) of the stage-one and stage-two participants, respectively, as revealed from the first section of the questionnaires.

Table 1. Background data of stage-one participants

\begin{tabular}{|c|c|c|c|c|}
\hline Role & & Description & $\begin{array}{c}\text { No. of } \\
\text { Participants }\end{array}$ & $\begin{array}{c}\text { Percent of } \\
\text { Participants }\end{array}$ \\
\hline \multirow[b]{2}{*}{$\begin{array}{c}\text { Teachers } \\
\mathrm{N}=18\end{array}$} & Education & $\begin{array}{c}\text { Certification } \\
\text { B.Ed./B.A. } \\
\text { M.A. }\end{array}$ & $\begin{array}{c}2 \\
13 \\
3\end{array}$ & $\begin{array}{l}\% 11 \\
\% 72 \\
\% 17\end{array}$ \\
\hline & Experience & $\begin{array}{c}1-10 \text { years } \\
11-20 \text { years } \\
21-30 \text { years } \\
\text { more than } 30 \\
\text { years }\end{array}$ & $\begin{array}{l}4 \\
7 \\
5 \\
2\end{array}$ & $\begin{array}{l}\% 22.2 \\
\% 38.8 \\
\% 27.7 \\
\% 11.1\end{array}$ \\
\hline \multirow[b]{2}{*}{$\begin{array}{c}\mathrm{IA} \\
\mathrm{N}=12\end{array}$} & Education & $\begin{array}{c}\text { High school } \\
\text { B.A. }\end{array}$ & $\begin{array}{l}8 \\
4 \\
\end{array}$ & $\begin{array}{l}66.7 \% \\
33.3 \% \\
\end{array}$ \\
\hline & Experience & $\begin{array}{l}0.5-1 \text { years } \\
2-10 \text { years } \\
11-16 \text { years }\end{array}$ & $\begin{array}{l}6 \\
5 \\
1\end{array}$ & $\begin{array}{c}5 \% 0 \\
\% 41.7 \\
8.3 \%\end{array}$ \\
\hline
\end{tabular}

Table 2. Background data of stage-two participants

\begin{tabular}{|c|c|c|c|c|}
\hline Role & Degree & Description & $\begin{array}{c}\text { No. of } \\
\text { Participants }\end{array}$ & $\begin{array}{c}\text { Percent of } \\
\text { Participants }\end{array}$ \\
\hline \multirow{4}{*}{ IA } & \multirow{2}{*}{ Education } & High school & 4 & $50 \%$ \\
& & Matriculation & 2 & $25 \%$ \\
\cline { 2 - 5 } & Experience & BA & 2 & $25 \%$ \\
\hline & 2-4 years & 4 & $5 \% 0$ \\
\hline
\end{tabular}

Table 1 shows that the participants represent a typical cross-section of teachers and TAs from the aspects of both education and experience.

There was a significant difference between the education level of the teachers and the IAs $\left\{\chi^{2}(2)=10.833, p<0.005\right\}$. Most of the participating teachers $(89 \%)$ had university degrees, three of whom had an M.A. Two teachers $(10 \%)$ held only a certificate in education. (In all probability, these two teachers, who were also those with the most experience [30 and 37 years], began working when non-academic qualification for teaching was more the norm). On the other hand, the majority of the IAs (66.7\%) held only a high school diploma and the others $(33.3 \%)$ held undergraduate degrees in areas other than teaching.

With respect to experience, about one fifth of the teachers $(22.2 \%)$ had been working for between one and ten years, $38.8 \%$ between 11 and 20 years, about one quarter $(27.7 \%)$ between 21 and 30 years and a little over a tenth (11.1\%) over 30 years. On the other hand, about a half of the IAs had been working less than a year, $41.7 \%$ between two to ten years, and only one had been working for 16 years.

The stage-two participants (IAs only) show a similar cross-sectional picture: half had had only completed grade 12, a quarter had matriculation certificates, and a quarter held undergraduate degrees. Regarding experience, half had been working less than one year, and the other half between two to four years.

\subsection{Tools and Procedures}

Data collection was by means of questionnaires and in-depth, semi-structured interviews. After the initial data analysis, the questionnaire underwent some revision, as detailed below.

\subsubsection{Stage-one questionnaire}

A two-part questionnaire was prepared based on one entitled "Assistant-given support for SEN students in the general education setting as assigned by the Department of Special Education." and used by The National Authority for Evaluation in Education (RAMA) in 2008-9 as part of all-encompassing effort to survey the role-players in the special education field: regional support center directors, chairs of the inclusion committees, classroom and kindergarten teachers (regular classrooms), classroom and kindergarten teachers (integrated classrooms), assistants (TAs and IAs), parents, and students. The purpose of that survey was to comprehend and map the decision-making procedures taken by the various committees regarding determining eligibility for IA support, the patterns of behavior of the IAs, and the perceptions of different role-players regarding the IAs' effectiveness. The original questionnaire had medium-to-high internal reliability for each statement relating to the IA's role $(\alpha=0.90-0.64)$, and an explained variance of $59.4 \%-66.1 \%$.

For the present study, we used the part of the questionnaire that was intended to identify and map the teachers' and IAs' perceptions of the IAs' role. This questionnaire was found to have a high internal reliability $(\alpha=0.823)$.

The first part of the questionnaire asked for information regarding education, experience, amount of guidance/instruction received (if any) for working with included students, and two questions regarding the participants' involvement in any decision-making regarding eligibility of the student for assistance and the amount of support and guidance the IA receives during for her role.

The second part of the questionnaire comprised 30 statements divided into five categories (6 statements each), in which the IA is involved: education, behavior, coordination, and communication between role-players, interpersonal communication and social acceptance, and organization and mobility. Participants were asked to rate each of the statements on a Likert scale of 1 to 6 ("not relevant at all" to "very relevant").

Table 3 gives some examples of statements from each of the categories and their reliability factor of each category. 
Table 3. Examples of statements in each category and reliability factor

\begin{tabular}{|c|c|c|}
\hline Category & Reliability factor & Example statements \\
\hline Education & $\alpha=0.726$ & $\begin{array}{l}\text { Explains and mediates for the student the subjects learned in class. } \\
\text { Helps the student practice and memorize the learned subjects. }\end{array}$ \\
\hline Behavior & $\alpha=0.855$ & $\begin{array}{l}\text { Reminds the student what are the accepted norms of behavior among the children. } \\
\text { Calms the student and makes sure that the student does not interfere in the lessons in class. }\end{array}$ \\
\hline $\begin{array}{l}\text { Coordination and } \\
\text { communication between } \\
\text { role-players }\end{array}$ & $\alpha=0.654$ & $\begin{array}{l}\text { Updates the general classroom teacher regarding what and how much can be expected from the } \\
\text { student. } \\
\text { Validates and communicates information to the various educational and care staff. } \\
\text { Takes responsibility to report to the parents what the functional level of the student regarding } \\
\text { lessons, behavior, and social interactions. }\end{array}$ \\
\hline $\begin{array}{l}\text { Interpersonal } \\
\text { communication and social } \\
\text { acceptance }\end{array}$ & $\alpha=0.838$ & $\begin{array}{l}\text { Encourages the student to express his feelings of frustration or joy to the teacher or his } \\
\text { classmates. Stands up for the student's rights when dealing with his classmates or the teaching } \\
\text { staff. }\end{array}$ \\
\hline Organization and mobility & $\alpha=0.553$ & $\begin{array}{l}\text { Organizes the student's personal belongings on his desk and in his backpack (inserts/removed } \\
\text { books, notebooks, writing implements, etc.). } \\
\text { Writes down for the student the main points of the lesson in his notebook or laptop. } \\
\text { Encourages the student to maintain cleanliness and order on his desk or in his backpack. }\end{array}$ \\
\hline
\end{tabular}

The questionnaire was handed out to participants either in the schools (during working sessions when one of the authors, in the capacity of a professional development instructor, met with the staff), or in professional development meetings in regional support centers.

The goal of the study was explained to the participants, and they were assured that their anonymity would be preserved and that the data gathered would be used only for the purpose of this research. After giving their permission to use the data, they were asked to fill out the information in the first part of the questionnaire (demographic information, seniority and education levels, and involvement with relevant decision-making processes). Then they were asked to rate the 30 statements in the second part of the questionnaire.

Filling out the questionnaire took about one-half hour.

\subsubsection{In-depth Semi-structured Interviews}

In-depth, semi-structured interviews were conducted with a sampling of two teachers and two IAs. These interviews consisted of one open question asking the participant to describe the role of the IA and their experience regarding the inclusion of SEN students. Based on their answers, the interviewer asked more focused questions (based on the in the questionnaire's statements) regarding the role of the IA.

The interviews were filmed and transcribed for qualitative analysis.

\subsubsection{Revised Questionnaire for Teachers/IAS}

After analysis of the questionnaires and, especially, the interviews, it was clear that some of the participants had misunderstood a few terms in some of the statements. After deliberation, the authors reduced the number of statements to 20 in two main categories: functional and educational. This decision was influenced by amendment no. 7 to the Special Education Law (2002) which indicated that the roles of the IA are many and varied and focused on two levels: functional and educational.
In the revised questionnaire, functional statements included those such as "Is concerned that the student will organize and sort the educational materials in notebooks and file folder." Educational statements included "Imparts learning strategies to the student."

Thus, the 30 original statements were re-sorted into these categories and checked for reliability by five reviewers with $100 \%$ agreement. In addition, the reliability for the functional category was found to be $(\alpha=0.825)$ and for the educational category $(\alpha=0.658)$

\subsubsection{Stage-two: Post Course Questionnaire}

Based on the data gathered from the stage-one questionnaires and interviews, and following consultation of one of the authors with the IAs, a 20-hour professional development program for IAs was developed and was offered over four sessions of five hours each. The topics covered theoretical and practical aspects; familiarity with characteristics of disabilities of SEN students eligible for support; academic, social, and emotional considerations; working with the SEN student; insights into the educational system; an overview of the educational staff that accompanies SEN students; and case analyses that illustrate the complexity of the job and the dilemmas facing the IA. The content comprised one portion of a 180-hour, yearlong professional development course. The training was carried out in a regional college.

Eight IAs (all of whom had signed up for the course of their own volition and financed their studies themselves) attended. They were asked to fill out the questionnaires both before and after the course. Two of the participants underwent semi-structured, in-depth interviews, and then a summary discussion was conducted with all eight during which they were asked to describe if an how they felt the course contributed to their perceptions of their role as an IA and to define future needs. 


\section{Data Analysis}

The data gathered from the questionnaires were coded and analyzed quantitatively: Stage-one data underwent quantitative analysis within and between groups to identify and compare how teachers and IAs perceived the TA's role for each of its separate aspects. Stage-two data were analyzed to determine how the course affected the IAs' perceptions of their role.

The interviews underwent content analysis by two of the researchers with regard to the various aspects of the IA's role.

\section{Results}

\subsection{Analysis of Initial Stage-one Questionnaire}

\subsubsection{Involvement with decision-making}

To analyze the difference regarding IAs' and teachers' involvement (if any) in the decision-making process regarding eligibility and amount of support granted to the SEN student, $\chi^{2}$ analysis was conducted. No significant difference was found between the two groups $\left\{\chi^{2}(1)=1.22\right.$, $\mathrm{p}>0.05\}$. The vast majority, $72.4 \%$, of the participants had no involvement whatsoever in the decision-making process. Nevertheless, it was clear that more teachers (35.3\%) were involved in such decision-making compared to the IAs (16.7\%).

Examples of answers from IAs:

- "I am hired for this job based on the requirements of the system after the committees have met and defined eligibility criteria. I am not involved in the preliminary meetings."

- "I was informed quite close to the beginning of the academic year that I would be accompanying a student with a severe disability, and began working a few days after the beginning of the academic year without any prior notice. Of course, I wasn't involved in any of the decision-making meetings."

- "I don't believe I am even supposed to be present in such meetings."

Examples of answers from teachers:

- "I am only involved in cases where the student was already studying in the school, and the process of detecting and diagnosing the disability took place during this time. I am not involved in the process of decision making for a student who is newly arrived to the system."

- "I am informed quite close to the beginning of the school year who my students will be. If there are any pupils receiving assistance, the student counsellor updates me."

- "I am involved in the decision-making process only when a student is already in my class and is progressing to the next grade with me."
- "I am involved in the process only in cases where we notice that one of my students is having difficulty and undergoes diagnoses and definition of his disability while he is in my class."

\subsubsection{Eligibility for receiving support from an IA}

Regarding the opinions of teachers and IA about amount of eligibility for support from an IA, there were no differences found between the teachers and the IAs. They all responded that the eligibility was justified.

\subsubsection{Receiving Guidance}

A significant difference was found $\left\{\chi^{2}(2)=6.123, p<\right.$ $0.005\}$ between the amount of assistance or professional guidance teachers and IAs received to prepare them for working with SEN students: The IAs received more professional guidance than the teachers did.

$41.7 \%$ of the of the IAs reported frequently receiving professional guidance, a similar percentage of IAs reported occasionally receiving guidance, and $16.7 \%$ reported never receiving any guidance. On the other hand, $61.4 \%$ of the teachers reported that they had never received any guidance, $14.3 \%$ reported receiving occasional guidance, and $24.3 \%$ reported receiving frequently guidance.

One of the IAs reported: "I receive guidance from a range of sources. The parents guide me, or, if needed, the counsellor brings in an expert or someone from the regional support center."

A teacher reported, "I don't have time during the day to leave the class for individual guidance regarding the child. Any guidance I receive usually occurs during the professional meetings regarding his status."

Perceptions regarding the IA's role

To examine the differences between teachers and IAs with respect to their perceptions of the role of the IA in a general sense, a t-test was carried out. This study found a clear difference between teachers and IAs $\{\mathrm{t}(28)=1.801, \mathrm{p}<$ $0.05\}$.

Below are the results for each of the categories examined in the first part of the survey, a $\chi^{2}$ analysis of the Likert-scale responses is presented along with relevant quotes from the interviews.

\subsubsection{Education}

The statements here dealt with adaptation of learning materials, encouraging the student to cope with complex learning tasks, helping the student practice and memorize the material, and more.

Overall, the teachers and IAs seemed to be in agreement regarding the IAs' role in helping the SEN-student to learn and there was no significant difference found between the teachers or the IAs in any of the statements in this area. Nevertheless, a $\chi^{2}$ analysis of two of the statements did reveal significant differences in two statements.

For "Adapts the study and demonstration materials to the student according to the instructions of the teacher," $83.3 \%$ 
of the teachers reported that preparation or adaptation of learning materials was not part, or only slightly part, of the IA's role. On the other hand, $70 \%$ of the IAs reported that their job involved a large or vary large amount of preparation of learning materials $\left(\chi^{2}=7.964, \mathrm{p}<0.005\right)$.

"Explains and mediates the material taught in class to the student." Most of the teachers (76.5\%) indicated that the IA's role does not include explaining or mediating the material taught in class, whereas $80 \%$ of the IAs stated claimed that their role did include explaining and mediating the material taught in class $\left(\chi^{2}=8.132, \mathrm{p}<0.050\right.$. $)$

- Teacher: "The IA doesn't provide material and doesn't mediate it, but only practices the material according to my instructions."

- IA: "Of course I teach the material. Without me, the student would not have learned to read. We go out of the classroom together and I adapt the program of studies for the class.

- IA: "I teach the child reading, writing, mathematics, and even English. Without me, he wouldn't have progressed at all."

\subsubsection{Behavior}

The teachers and IAs were asked to relate to statements dealing with accepted social norms. A $\chi^{2}$ analyses found a significant difference between the teachers and the IAs in only one statement out of the six: "Reminds the student what he must do to concentrate and pay attention in lessons": 100\% of the teachers indicated that this was the IA's job, whereas only $70 \%$ of the IAs thought so $\left\{\chi^{2}=4.093, p<0.05\right\}$.

For the other five statements in this category, there were no significant differences found between the teachers and the IAs. Most of the participants believed that the all the following were part of the IA's job: concern for the safety of the student, advising him what the accepted behavioral norms are among his classmates, calming him, and ensuring that he does not disrupt the class.

- IA: "The SEN student is like all the children in the class. If the teacher reprimands the others, she should also be the one to reprimand him."

- Teacher: "The IA is the one who sits next to the child and immediately sees his situation; therefore it is her job to reprimand him about his behavior."

\subsubsection{Coordination and communication between different role-players}

Statements in this category referred to issues involving coordination and communication between the various role-players involved with the SEN student: parents, professional teachers, classroom teacher, and therapy personnel. The $\chi^{2}$ analyses found clearly significant differences between the teachers and the IAs in three statements out of the six, and a lower significant difference in one other statement.

"Informs the school regarding unusual events during recess (arguments with classmates, injury, etc.)" One IA only but 12 teachers believed that that this was part of the
IA's job $\left(\chi^{2}=7.289, \mathrm{p}<0.5\right)$.

"Refers the parents to the class teacher to obtain updates regarding how their child is doing with respect to studies, behavior, and social situation." All of the teachers believed that this was not the role of the IA, but the majority of IAs $(60 \%)$ believed that it was. $\left(\chi^{2}=11.111, p<0.05\right)$.

"Is responsible for reporting to the parents how their child is doing with respect to studies, behavior, and social situation." Most $(87.5 \%)$ of the teachers believed that this is not the IA's role, while most $(60 \%)$ of the IA's believed that it was $\left(\chi^{2}=5.297, \mathrm{p}<0.05\right)$.

For the statement "Directs the regular teaching staff regarding what and how much to demand from the student," $87.5 \%$ of the teachers and $60 \%$ of the IAs believed that this was not the role of the role of the IA (i.e., only $40 \%$ of the IAs believed that this was part of their job) $\left(\chi^{2}=3.222, p<\right.$ $0.073)$. The significant difference between the two groups is low, but it still indicates difference in their perception of the IA's roles.

- Teacher: "It is not appropriate for the IA to give information to the parents since she lacks professional understanding and might occasionally give misleading information or sensitive information that has not been coordinated. I, as the class teacher, I am the one who has been delegated to this task."

- Teacher: "The role of the IA is to update me. The directive is clear. I am the only one who is supposed to update the parents or professional staff about the child."

- IA: "The parents contact me every day by phone, e-mail, or in person and ask how their child's day was, and I feel it is my job to give them this information since I am most in contact with the child."

- IA: "I am in contact with the parents and with school staff and update them if there was any difficulty that day or if I see that there is any change. The parents themselves approach me almost every day."

\subsubsection{Interpersonal Communication and Social Integration}

This category-included statements regarding supporting and encouraging students to express their feelings, ensuring the rights of the child, and brokering and mediating between the student and his classmates. The $\chi^{2}$ analyses found only one statement of the six to show a significant difference between the teachers and the IAs: "Encourages the student to express his feelings of frustration or joy to peers or teachers." $53.3 \%$ of the teachers thought that this was not the role of the IA, but $90 \%$ of the IAs believed that this was the role of the IA $\left\{\chi^{2}=4.279, \mathrm{p}<0.05\right\}$.

The other five other statements aspect this category showed no significant differences between the teachers' and IAs' perceptions regarding the role of the IA.

\subsubsection{Organization and mobility}

This category-included issues regarding the personal belongings, appearance, and mobility of the student. No significant differences were found between the groups in all 
the statements in this category. It seems that in this case, the role of the IA is clear to both sides.

\subsection{Analysis of Revised Stage-one Questionnaire}

A further analysis of the questionnaire was carried out after the five original categories had been reduced to only two: the role of the IA in the educational area, and the role in the functional area. A significant difference was found in the educational category between the perceptions of the teachers and IAs $\{\mathrm{t}(28)=2.1, \mathrm{p}<0.05\}$, but no significant difference was found in the functional category $\{\mathrm{t}(28)=0.362$, $\mathrm{p}=0.36\}$.

- IA: "My job is to accompany the child, make sure he is all right, feels good, understands what is expected of him, has the necessary material, and is updated."

- Teacher: "The role of the IA is to accompany the child in everything that is connected to the study day, help with his belongings, taking him to the different classes, watching him at breaks, with food, etc."

\subsection{Summary of the Analyses of the Stage-one Data}

- While $72.4 \%$ of the participants in the study were not involved in the decision making process regarding support for the integrated student, more teachers were involved than IAs. However, the teachers are clearly more involved in such decision making than the IAs.

- IAs receive significantly more professional training and guidance for working with SEN students than the teachers do.

- In the area of organization and mobility, there was no difference found between the two groups regarding their perceptions of the role of IA; in the areas of behavior and interpersonal communication, and social integration, there was a significant difference in only one of the six statements.

- In the educational area, significant differences were found in two out of six statements.

- The most significant differences between the perceptions of the teachers and the IAs were found in the area of coordination and communication between role-players (significant differences in four out of six statements).

- When presented as just two categories (educational and functional), it was evident that the teachers and IAs were almost in full agreement regarding the functional tasks of the IA, but exhibited significant differences with respect to educational tasks.

\subsection{Analysis of Stage-two Data}

We analyzed the influence of a professional development brief course on the IA's perception of her role by having them fill out a questionnaire before and after participating in the course. The t-test analysis carried out did not find any significant differences in the IAs' perceptions before and after the course. However, the interviews conducted with two of the participants-indicated that they felt that the course had contributed to their skills.

- "I feel that I got a lot. Now I better understand the disabilities of the child and how it is expressed in class."

- "It really helped that I could ask questions freely and use examples of my experience in class."

- "I believe that I need yearly training, and not just from a course."

\section{Discussion}

This exploratory study was designed to give a general overview of the reality in which IAs work and to identify and compare the perceptions of teachers and IAs with respect to various aspects of the IA's role. It also examined if a professional development course affected IAs' perception of their roles.

An analysis of the data that was collected in the study by questionnaires and interviews shows that while there are some aspects of the role of the IA where teachers and the IAs are in full agreement, there are some significant differences regarding other aspects.

DGC 4371/10(a) (2011) stipulates that "the assistive services, including those of the IA, are part of the measures for meeting the educational goals and objectives that will be determined in the student's individual program, so as to promote his or hers independence and ability for direct communication with the educational staff and classroom peers."

The standing of the Ministry of Education is that the IA's role is to assist the student in the classroom to understand the lesson and perform the tasks, removing this burden from the classroom teacher and allowing her to work with the all the pupils equally, including those with special needs. However, although the Ministry of Education views the IA to be part of an integrated support package offered to an SEN student, it does not differentiate between TAs, who work in special education classrooms, and IAs, who work in the general classroom, and lumps them both into the same general category. In practice, however, special education systems are intrinsically different from general education ones, and it is therefore clear that the role of in the IA in the general education setting is quite different than that of her counterpart in the other. In the special education system, the entire staff has been trained to work with SEN students and the role of the assistant is a part of the total support system. The staff does not depend on the assistant to allow effective teaching within the classroom. In the case of inclusion, however, the picture is quite different. The SEN student in the general education setting has minimal support and assistance from specially trained special education staff and must rely much more on the IA, who accompanies the student almost constantly throughout the educational setting. 
Thus, the IA's role is more crucial than in special education because she plays such a central role in the SEN student's academic success. While the SEN student does receive attention from special education staff, it is intermittent and certainly not as continuous as in the special education environment, and this void is therefore filled by the IA. It would seem obvious that such a person should be well skilled for whatever tasks are required for working with the SEN students and be well versed in applicable means of support.

\subsection{Discussion of Education, Involvement, and Guidance}

The results from the first part of the questionnaire were not surprising in lieu of the procedures and demands of the various DGCs pertaining to the hiring of IA staff.

For example, the significant difference found overall in the level of education between teachers (mostly academic degrees) and IAs (mostly with only high school education) is in keeping with the directive in DGC 4371/10(a) (20011) which stipulates that the only qualification required for an IA (either in the special-education framework or in the general education system) is twelve years of education. This despite the fact that their level of their education can have an effect on their roles, and that the high-school curriculum offers no information regarding educational concepts in general or the characteristics of the population with special needs in particular.

Our findings that most of the participants were not involved in decision-making processes regarding the assignment of an IA to an SEN student can be understood in light of the DGC directive that the committees making such decisions are to convene towards the end of the preceding academic year (March to May), well before the teachers and the IAs receive their assignments (DGC 4371/10(a), 2011).

The final question in this part of the survey related to the guidance provided to the teachers and the IAs to assist them in coping with the SEN students. The results indicated that most of the teachers and some of the IAs received no (or very little) professional guidance from any source whatsoever, and that those IAs who did receive guidance reported that they received it only after they had begun working with the SEN student. This situation points to a significant problem entailed in the general policy of inclusion and that reflects the reality in which since the IA is expected to begin a challenging and skill-demanding job with a child with complex disabilities without any preliminary training.

This incongruity is further multiplied because the classroom teacher, unlike teachers in the special education setting, has never received any instruction regarding SEN students, and is herself not fully aware of the implications of teaching students with severe disabilities. Even though she is in need of relevant professional guidance herself, she is nevertheless expected to guide the IA. This is in keeping with the findings of a study dealing with the perceptions of policy makers regarding the integration of SEN-students into the general education setting [20] that suggested that teachers in the general education setting do not acquire enough knowledge during their pre-service training to enable them to meet the needs of SEN-students, nor have the proper qualifications to advise IAs on the various facets of her job. The consequences of this situation are not surprising: the IA, without sufficient training and without sufficient support, must cope on her own every day with all the difficulties and challenges that come with working with an SEN student (some of whom are severely disabled), that are even more intensified due to the inappropriate support the student receives as a result of being in a general education setting.

The results described points to some serious issues that need to be addressed regarding the policy of including SEN students into a general education setting, and include issues regarding the appropriate education level expected in an IA, the lack of professional training for the job, the lack of training and guidance for the teachers in the integrated classroom setting, and, parenthetically, the lack of continuous professional support for the SEN student, who are being forced to enter a framework in which those responsible for them are not proficient nor trained for their roles.

\subsection{Discussion of Role Perceptions}

The primary purpose of the study was to compare the perceptions of teachers and IAs regarding a number of categories associated with the role of the IA in the general classroom setting: educational, behavior, coordination and communication between role-players, interpersonal communication and social acceptance, and organization and mobility.

The area in which the most significant differences were found is the educational one. Apparently, as reflected in the individual statements made by the IAs, the IA's lack of didactic training affects her understanding of various pedagogic terms, such as "acquisition," "facilitation of learning," and so on. For example, an IA, who must help the SEN student with a worksheet and explains the material or the instructions to the student, feels that her role is one of "teaching" the subject or even mediating in the educational process, while the teachers, who are more aware of these concepts, do not perceive these actions to actually be teaching and mediating, and thus the reason for their response. That is to say, one (the teacher) views this particular action as "assistance" while the other (IA) views the same action as "teaching."

Another category in which significant differences were found regarding some of the statements was that of coordination and communication between role-players. Here, too, this may be due to the IAs' lack of training for their role, which does not qualify them to make adequate reports regarding the achievements and difficulties of the student to administration, staff, or parents. Perhaps the IA considers administrative and other authoritative figures to be unapproachable, given that her last contact with school administrators probably occurred when she was a student, or a mother of a child in the educational system. Now, however, 
she is thrust into the position of having to understand the professional and personal dynamics that play out in the hierarchal structure of the school, and being sensitive to the interplay between the role-players. The various situations that can arise between her and the classroom teacher can be challenging on both personal and professional levels. Therefore, for example, when an SEN student is involved in some social-based incident during recess, the IA will report it to the teacher but not to the administration, even if the result of such is that the report to the administration is delayed because if the intermediation of the teacher. Another facet connected to the issue of training is that the teacher, aware of the IA's minimal training, may have doubts concerning the IA's qualification or skill to report to parents about the academic and emotional standing of their child. In contrast, a large proportion of IAs believe that they are the ones who should report to the parents since they spend the greatest amount of time with the student each day.

Considering the various answers given, it seems that the IAs' responsibility is to report technical issues (either to the teacher or the administration), but not instructional or educational issues (to the parents).

In contrast to the two areas mentioned above, where significant differences were found pertaining to a number of statements, the teachers and IAs appear to be in tandem regarding their perceptions of the IA's roles in the area of organization and mobility. In both the areas of behavioral and interpersonal communication and social integration, there was only one statement that showed any difference between the two groups. The fact that there are only minor differences here points to clear definitions of the role of the IA in these areas, possibly because they are based on the traditional role of the teacher's assistant in general.

The above seems to indicate that the problems associated with the IA's roles stem from the lack of theoretical and practical training regarding working with inclusion students. It is crucial that every IA - before beginning her role in the classroom - receives training regarding understanding the characteristics of students with special needs, familiarity with the teaching and mediation methods, and how to adapt didactic material for SEN-students. Furthermore, it goes without saying that if teachers in today's reality of inclusion learn about what is involved in introducing SEN students into their classroom sometime during their pre-service training, they would be much more able to teach an inclusion class and guide the IAs assigned to SEN students in their classes.

Analysis of the questionnaires in the second stage of the study suggests that a brief professional development course (one segment of a year-long program) has minimal influence on the perceptions that IAs have regarding their role. However, while such a short course may not be expected to bring about a significant change in the IA's perception of her role, the feedback obtained during the interviews and summary discussion of the course, suggests that the course, despite its brevity, did make the IAs more aware of how important training and professional, individual accompaniment throughout their job are. It is possible that the results showing the minimal influence of the course are due to the small sample set or its short duration (20 hours). It is worth noting that the length of the complete professional development course is only a portion (180 hours) of what the Dorner report recommended, which is 400 academic hours of study. Indeed, a survey of the IA training courses available in Israel reveals that none of the programs meets the requirements (programs range from 120 to 300 hours in length). It is hard to assume that a significant change in the perception of the role of the IA will come about as a result of such a minimal amount of study hours (20 hours) and considering the great gaps in knowledge that exist amongst the population of IAs. Nevertheless, even this minimal number of hours initiated awareness of the need for training.

Even though the Dorner committee recommended that a certificate be a prerequisite for hiring IAs, we did not discover any school that followed this recommendation, meaning that the present situation remains the status quo. In light of the continuing rise in the number of students with severe disabilities who are being included into the general education setting, the situation will only get worse.

\section{Conclusions}

The results of the first stage of this exploratory study point to the need to clearly define the role of the IA in the general education system and to clearly differentiate this role from that of the TA working in special education. It is important to precisely describe the skills required for the role. This is especially important given the large number of IAs currently employed in the general education setting.

The results of the second stage point to the need to expand and broaden the IA's training, something that should be grounded in legislative changes that stipulate pre-service training for IAs before they are accepted to the role, and professional guidance throughout.

\section{REFERENCES}

[1] Y. Lazer. Special education looks to the future: Topics for review and discussion, Sugiyot b'hinuch miyuhad v'shikum [Issues in Special Education and Rehabilitation] Vol. 15, No. 2, 63-72, 2000 [in Hebrew].

[2] UNESCO (1994). Final report - World conference on special needs education: Access and quality. Paris: UNESCO

[3] S. Mackenzie. "Yes, but ..": rhetoric, reality and resistance in teaching assistants' experiences of inclusive education, Support For Learning, Vol.26, No. 2, 64-71, 2011.

[4] A. Howes. Teaching reforms and the impact of paid support on participation and learning in mainstream schools, Support for Learning Vol. 18, 147-153, 2003. 
[5] B. Groom, R. Rose. Supporting the inclusion of pupils with social, emotional and behavioural difficulties in the primary school: The role of teaching assistants, Journal of Research in Special Educational Needs, Vol. 5, 20-30, 2005.

[6] D. Appl. First-Year Early Childhood Special Education Teachers and Their Assistants: "Teaching Along With Her". Teaching Exceptional Children, Vol. 38, No. 6, 34-40, 2006.

[7] P. Blatchford, P. Bassett, P. Brown, C. Martin, A. Russell, R. Webster. Deployment and impact of support staff project, DCSF, London, 2009.

[8] C. Devecchi, M. Rouse. An exploration of the features of effective collaboration between teachers and teaching assistants in secondary schools. Support for Learning, Vol. 25, No. 2, 91-99, 2010.

[9] L. L. Florian. The more things change the more they stay the same? A response to the audit commission's report on statutory assessment and statements of SEN, British Journal Of Special Education, Vol. 29, No. 4, 164-169, 2002.

[10] D. Appl. First-Year Early Childhood Special Education Teachers and Their Assistants: "Teaching Along With Her". Teaching Exceptional Children, Vol. 38, No. 6, 34-40, 2006.

[11] M. Takala. The work of classroom assistants in special and mainstream education in Finland. British Journal Of Special Education, 34(1), 50-57, 2007.
[12] Director General Circular No. 4358/10(c) Jerusalem: Ministry of Education, June 1, 1998 [in Hebrew].

[13] Special Education Law of 4360, Amendment no. 5, 2000 [in Hebrew].

[14] Special Education Law of 4363, Amendment no. 7, 2002 [in Hebrew].

[15] Dorner Committee. The public committee for examination of the special-education system in Israel: A report. Jerusalem: Ministry of Education, 2009) [in Hebrew].

[16] Central Bureau of Statistics. Statistical Abstract of Israel 2013 No. 64. CBS, Jerusalem, 2013 [in Hebrew].

[17] Director General Circular No. 4365/9(a) from May 1, 2005. Jerusalem: Ministry of Education [in Hebrew].

[18] Director General Circular No. 4368/3(d) from Nov. 1, 2007. Jerusalem: Ministry of Education [in Hebrew].

[19] Director General Circular No. 4371/10(a) from June 1, 2011. Jerusalem: Ministry of Education [in Hebrew].

[20] G. Avisar, A. Gilor, P. Licht, P. Shavit. The conceptions of policy makers regarding the inclusion of students with special needs in the general educations system: Implications regarding the training and professional development of teachers and kindergarten teachers - stage 2. Machon Mofet, Tel Aviv, 2013 [in Hebrew]. 